\title{
A Study on Maternal and Perinatal Outcome in Referred Obstetric Cases of Gestational Age More Than 28 Weeks in a Rural Medical College Hospital
}

\author{
${ }^{1}$ Nidhi Jha, ${ }^{2}$ Indranil Dutta, ${ }^{3} \mathrm{~N}$ Gopal
}

\begin{abstract}
Background: Indian women of a child bearing age (15-45 years) constitutes $22 \%$ of the population. They are a vulnerable special group. The risk is due to pregnancy and childbearing. To decrease this risk and improvement of the maternal and perinatal outcome, a referral system has been introduced which decreases the risk by improving service delivery at the tertiary center level, by reducing the workload, by strengthening the infrastructure in the peripheries and by the effective utilization of this by the patients. Major causes of referral to a tertiary center includes preterm labor, preeclampsia, eclampsia, previous CS, Rh negative blood group, antepartum hemorrhage, postpartum hemorrhage and sometimes due to lack of manual resources. Liking the different levels of care was an essential element of primary health care from the very beginning.
\end{abstract}

Objectives: To identify the primary reasons and pattern of obstetric case referral to our hospital and to study the maternal and perinatal outcome in those cases.

Materials and methods: One hundred and fifty consecutive obstetric referred cases of more than 28 weeks gestation admitted to Sri Adichunchanagiri Hospital and Research Centre were analyzed for the maternal and perinatal outcome.

Results: In this study of the total studied patient's majority were in the group $21-25$ years constituting about $60.6 \%$. Nearly $38.7 \%$ of the referral was from THQ covering the areas like Nagamangala, Kunigal, Turuvekere and Channarayapattana. $28.7 \%$ were from $\mathrm{PHC}, 12 \%$ were from $\mathrm{CHC}, 6.7 \%$ from district hospital and $14 \%$ of the referral were from private hospital. Analyzing at the quality of referral according to the predefined criteria only $48 \%$ of the cases had adequate referral whereas about $28 \%$ of the cases had poor referral most of which were from the PHCs. About $58.8 \%$ of the patients delivered vaginally, with about $41.2 \%$ of the patient delivered by cesarean section. In the vaginally delivered cases $8.7 \%$ was instrumental delivery, $1.4 \%$ was breech delivery and $10.7 \%$ patient delivered after induction. In the present study major indication of the cesarean section include dystocia $29.1 \%$, fetal distress with or

${ }^{1}$ Assistant Professor, ${ }^{2}$ Associate Professor, ${ }^{3}$ Ex-Professor

${ }^{1}$ Department of Obstetrics and Gynaecology, SGT Medical College, Gurugram, Haryana, India

${ }^{2}$ Department of Obstetrics and Gynaecology, IQ City Medical College, Durgapur, West Bengal, India

${ }^{3}$ Department of Obstetrics and Gynaecology, Adichunchanagiri Institute of Medical Sciences, Belur, Karnataka, India

Corresponding Author: Indranil Dutta, Associate Professor, Department of Obstetrics and Gynaecology, IQ City Medical College, Durgapur, West Bengal, India, mobile: +919831476666, e-mail: drindranildutta@gmail.com without meconium aspiration $20.9 \%$, hypertensive disorders of pregnancy $17.7 \%$, repeat section $11.3 \%$, malpresentation $8.1 \%$ and others $12.9 \%$. About $86.1 \%$ of the referral has been made with an obstetric indication. $12.6 \%$ of the referral had a medical indication for referral. Only $1.3 \%$ of the cases had a lack of manual resource as an indication for referral. Preterm labor and PROM accounted for about $20 \%$ of the referral. Hypertensive disorders were the next commonest cause of referral of about $13.3 \%$ of the cases. In the present study, there were a total of 126 live births, 5 stillbirths and 7 early neonatal deaths making the perinatal mortality rate (PNMR) of 95.23 per 1000 live births. Perinatal outcome was best for patients with age group of 21-25 years and was worst for the age group for more than 30 years.

Interpretation and conclusion: Although better than the national data, there is indeed no doubt that rural health care infrastructure is falling short of the existing requirement. However, educating the population about the existing health care delivery system and sensitizing the public toward improving maternal and child health would go a long way in optimally utilizing the existing infrastructure and improving the maternal and perinatal outcome.

Keywords: Maternal outcome, Perinatal outcome, Referred cases.

How to cite this article: Jha N, Dutta I, Gopal N. A Study on Maternal and Perinatal Outcome in Referred Obstetric Cases of Gestational Age More Than 28 Weeks in a Rural Medical College Hospital. J South Asian Feder Obst Gynae 2018;10(Suppl 1): 302-309.

Source of support: Nil

Conflict of interest: None

Date of received: 11 February 2018

Date of acceptance: 15 October 2018

Date of publication: July 2019

\section{INTRODUCTION}

Indian women of childbearing age (15-45 years) constitute $22 \%$ of the population. They are an especially vulnerable group. The risk is due to pregnancy and childbearing. Antenatal care is a concept that extends from prepregnancy to postpartum, leading to effective emergency care for predictable and unpredictable complications during pregnancy and childbirth. ${ }^{1}$

There is a close relationship between the maternal and child health to the health of the family and of family's health to the general health of community. ${ }^{2}$

All pregnant women are at risk of developing obstetric emergencies. Most life-threatening complications occur 
during labor and delivery, and many of these cannot be predicted. These require skilled medical interventions such as cesarean delivery, blood transfusion, drug therapy, etc. ${ }^{3}$

The purpose of antenatal care is to identify high-risk cases from a large group of antenatal mothers and arrange for the timely and appropriate skilled care.

Referral system has been introduced in Karnataka, (a) to improve service delivery at tertiary center level, (b) to reduce the workload, (c) to strengthen the infrastructure in the peripheries and the effective utilization by the patients, (d) referral system at the same time also helps promote research and educational activities in the tertiary care level.

Major causes of referral to a tertiary center includes preterm labor, preeclampsia, eclampsia, previous CS, $\mathrm{Rh}$ negative blood group, antepartum hemorrhage, postpartum hemorrhage and sometimes due to lack of manual resources. Liking the different levels of care was an essential element of primary health care from the very beginning. The referral system was meant to complement the PHC principle of treating patients as close to their homes as possible at the lowest level of care with the needed expertise.

\section{MATERIALS AND METHODS}

Sri Adichunchanagiri Hospital and Research Centre is a rural medical college situated at BG Nagara, Belur, Mandya District around 110 kilometers away from Bengaluru. It is a tertiary care center. The majority of cases that we get here are referred cases. The patient population is mainly from low socioeconomic status, rural areas and also from private hospitals. The patients who are admitted here come from the surrounding areas, with minimal or no medical facilities, with a radius of about $100 \mathrm{~km}$ and the time taken to reach our institution would vary from 30 minutes to about 6 hours. This study includes all referred obstetric cases of more than 28 weeks of gestation. The cases are initially handled elsewhere by qualified and unqualified personnel. All the antenatal patients with inclusion criteria were followed up regarding the reasons for referral and are followed for the outcome. A thorough history was taken from all referred antenatal cases admitted to SAH and RC. Clinical examination done followed by obstetric examination including the height of uterus, contractions present or not, fetal position, FHS, etc., were recorded, P/S examination to check for leak/bleed PV, Bishops score was assessed by PV. Caput and molding were also noted if present. The pelvis was evaluated for disproportion. All outcomes and booking visits were defined on the basis of previously established standardized criteria.

\section{Criteria to Define the Quality of Referral}

Quality of been defined adequate, inadequate and poor according to whether the patient wasInvestigated, examined, diagnosis arrived, defined reasons for referral, timely referral, treatment was given or not proper information to the client given or not before referring her.

Referral from adhering to all the above-defined criteria is taken as an adequate referral. The form satisfying only four of the above is taken as an inadequate referral whereas the one with only two of the above criteria is considered as a poor quality referral.

\section{Type of Referral}

Referral is divided into two types according to the circumstances under which the patient is referred emergency referral was made in emergency cases which could not be totally managed at the health center. The elective referral was usually made to (a) seek expert opinion regarding a patient, (b) seek admission and management of a patient, (c) seek facilities for investigations.

\section{Criteria to Define the Condition of the Patient}

Condition of the patient was defined as stable, poor and critical according to the following criteria-general condition, vitals, the presence of end-organ damage

\section{RESULTS AND ANALYSIS}

\section{Study Design}

A prospective clinical study consisting of 150 patients is undertaken to study the maternal and fetal outcome. First, 150 consecutive referred cases that presented during the study period November 2011 to November 2013 were included. The various parameters that were recorded were analyzed for correlation with a poor maternal or fetal outcome. The demographic pattern was also studied.

In this study of the total studied patients' majority were in the group 21-25 years constituting about $60.6 \%$. Of the total studied patients' majority of them around $48 \%$ are of socioeconomic class III. Only $1.3 \%$ of patients are from a socioeconomic class $\mathrm{I}$, which is equivalent to an upper class. Only $6 \%$ of the patients are illiterate, and this is the reason for better utilization of antenatal care and relatively better outcome in my study. Majority of the referred cases belonged to the gestational age more than 36 weeks constituting about $84.7 \%$ of the referrals. $10.7 \%$ were in the gestational age group of 28-34 weeks, and $4.7 \%$ were in the group 34-36 weeks. Primigravidas constitute the majority of about $65.3 \%$ of the referral. Majority of the cases about $80 \%$ are booked, and only $20 \%$ of the cases are unbooked. 
Nearly $38.7 \%$ of the referral was from THQ covering the areas like Nagamangala, Kunigal, Turuvekere, and Channarayapattana. About $28.7 \%$ were from PHC, $12 \%$ were from $\mathrm{CHC}, 6.7 \%$ from district hospital and $14 \%$ of the referral were from private hospital. About $64 \%$ of the referrals have been made secondary to emergency indications (Table 1).

About $86.1 \%$ of the referral has been made with an obstetric indication (Tables 1 and 2). About $12.6 \%$ of the referral had a medical indication for referral. Only $1.3 \%$ of the cases had a lack of manual resource as an indication for referral. Preterm labor and PROM accounted for about $20 \%$ of the referral. Hypertensive disorders were the next most common cause of referral of about $13.3 \%$ of the cases.

Analyzing at the quality of referral according to the predefined criteria only $48 \%$ of the cases had adequate referral whereas about $28 \%$ of the cases had poor referral most of which were from the PHCs. Majority of the referrals about $66 \%$ in my study used 108 ambulances as the mode of transportation to reach the hospital. A private vehicle is used by $16.7 \%$ of the patients, hospital ambulance is used by only $4.6 \%$ of the patients, and $12.7 \%$ of patients chose public transport like auto as a mode of transportation. Among them, 108 was used mainly by educated people and auto by illiterate and lower socioeconomic class people. Out of all the referrals, $63.3 \%$ of the patients reached the center within 2 hours (Table 3),

Table 1: Causes for referral

\begin{tabular}{lll}
\hline Causes for referral & No. of mothers $(n=150)$ & $\%$ \\
\hline 1. PIH & 20 & 13.3 \\
2. Preterm labor & 15 & 10.0 \\
3. PROM & 15 & 10.0 \\
4. Obstructed labor & 11 & 7.3 \\
5. Fetal distress & 14 & 9.3 \\
6. Previous LSCS & 8 & 5.3 \\
7. Postdated pregnancy & 8 & 5.3 \\
8. Prolonged labor & 7 & 4.7 \\
9. Malpresentation & 6 & 4.0 \\
10. Anemia & 6 & 4.0 \\
11. APH & 6 & 4.0 \\
12. GDM & 5 & 3.3 \\
13. IUD & 5 & 3.3 \\
14. Cardiac disease & 4 & 2.7 \\
15. Eclampsia & 3 & 2.0 \\
16. Failed Induction & 3 & 2.0 \\
17. Hypertension & 2 & 1.3 \\
18. Jaundice & 2 & 1.3 \\
19. Multiple pregnancies & 1 & 0.7 \\
20. MISC & 9 & 6.0 \\
\hline
\end{tabular}

Table 3: Time interval

\begin{tabular}{lll}
\hline Time interval & No. of mothers $(n=150)$ & $\%$ \\
\hline$<2$ hours & 95 & 63.3 \\
2-4 hours & 49 & 32.7 \\
$>4$ hours & 6 & 4.0 \\
\hline
\end{tabular}

$34 \%$ of the patients reached the center in $2-4$ hours (Table 3 ). Only $2.7 \%$ of patients took more than 4 hours in reaching the center, this shows the prompt and good service of 108 ambulances in rural parts of Karnataka. A very high percentage of patients about $87.3 \%$ arrived at the center in stable condition. Only $2 \%$ of the patients arrived at the center in critical condition, this could be attributed to the improvement of transport facilities, increasing awareness among health care professionals and the patient compliance.

Of the total 150 cases, about $43(28.66 \%)$ cases required treatment before delivery and majority of them were treated by antihypertensives only (Table 4 ).

About $58.8 \%$ of the patients delivered vaginally, with about $41.2 \%$ of the patient delivered by cesarean section. In the vaginally delivered cases $8.7 \%$ was instrumental delivery, $1.4 \%$ was breech delivery and $10.7 \%$ patient delivered after induction.

In the present study, major indication of the cesarean section include dystocia $29.1 \%$, fetal distress with or without meconium aspiration $20.9 \%$, hypertensive disorders of pregnancy $17.7 \%$, repeat section $11.3 \%$, malpresentation $8.1 \%$ and others $12.9 \%$. No maternal death was noted in our series. About $8.7 \%$ of the cases needed a blood transfusion. Fifteen $(9.33 \%)$ of the patients needed intensive monitoring either in the labor room or in intensive care unit.

In the present study, there were a total of 126 live births, five stillbirths and seven early neonatal deaths making the perinatal mortality rate (PNMR) of 95.23 per 1000 live births, which shows a much better outcome than the other similar studies. More than $1 / 3$ rd of the neonate required a NICU admission. This is expected in high-risk

Table 2: Causes for referral: Miscellaneous

\begin{tabular}{lll}
\hline Causes for referral: Misc & No. of mothers $(n=9)$ & $\%$ \\
\hline 1. Handprolapse & 1 & 11.1 \\
2. Cord prolapse & 1 & 11.1 \\
3. CPD & 1 & 11.1 \\
4. Oligohydramnios & 1 & 11.1 \\
5. Polyhydromnios & 1 & 11.1 \\
6. Precious pregnancy & 1 & 11.1 \\
7. Anomalous baby & 1 & 11.1 \\
8. HIV+vs & 1 & 11.1 \\
9. RH-ve & 1 & 11.1 \\
\hline
\end{tabular}

Table 4: Treatment given before delivery

\begin{tabular}{lll}
\hline Treatment given & No. of mothers $(n=43)$ & $\%$ \\
\hline Antihypertensive & 13 & 30.23 \\
Tocolytics and steroid & 12 & 27.91 \\
MgSO $_{4}$ & 7 & 16.28 \\
Insulin & 4 & 9.30 \\
Blood transfusion & 4 & 9.30 \\
SBE prophylaxis & 3 & 6.98 \\
Total & 43 & 100.0 \\
\hline
\end{tabular}


pregnancies with complications. The main reason for NICU admission was birth asphyxia. The other reasons were low birth weight, transient tachypnoea of newborn and septicemia.

Maternal outcome was relatively poor in multiparous patients when compared to primigravidas, but it was statistically not significant. No difference in outcome was seen in relation to gestational age. Maternal outcome was poor when the time interval to reach the tertiary center was more than 4 hours and we got statistically significant regarding this.

Perinatal outcome was best for patients with age group of 21-25 years and was worst for the age group for more than 30 years. A better outcome was seen in booked cases but it was not statistically significant. There was an increased number of intrauterine deaths when travel time was more than 4 hours, which says these deaths could have been prevented with better access to the tertiary healthcare center.

\section{DISCUSSION}

This study is conducted in Adichunchanagiri Institute of Medical Sciences, BG Nagara, Mandya district reflects the results obtained from a tertiary care center. There were certain limitations in the study as pregnancies less than 28 weeks of gestation were not included, and so were the postnatal patients.

\section{Maternal Characteristics and its Influence on Outcome}

Age in the present study, $60.6 \%$ of all referrals were in the age group 21-25, usually considered to be a low-risk group. The present study demonstrates that the majority of the patients that require a referral belong to this age group. Hence, the "at risk" approach for better utilization of scarce resources is not rational and pregnancies in this age group are equally liable to complicate if not monitored and also these complications cannot be predicted with reasonable accuracy. Limaye et al. ${ }^{4}$ has age group between 15 years and 30 years as $89.20 \%$ and more than 35 years as $3.20 \%$.

As evident from the Table 5, the above percentage of patients in the individual age group were comparable.

Data of the National Family Health Survey (NFHS)-3 revealed that $16 \%$ of women, aged $15-19$ years (Table 6 ), have already started childbearing (Table 7$)$. This proportion is the highest in the state of Jharkhand (28\%), followed by West Bengal (25\%) and Bihar (25\%), all located in eastern India. ${ }^{5}$

In the present study, teenage pregnancies made up $6.7 \%$ of all referrals (Table 8 ), which is less than half of the national average. This could be due to better educational level and higher socioeconomic status than the national average.
Table 5: Correlation of clinical variables with maternal outcome

\begin{tabular}{|c|c|c|c|}
\hline \multirow[b]{2}{*}{ Variables } & \multicolumn{2}{|c|}{ Maternal outcome } & \multirow[b]{2}{*}{$p$ value } \\
\hline & $\begin{array}{l}\text { Good } \\
\text { outcome } \\
(n=122)\end{array}$ & $\begin{array}{l}\text { Poor } \\
\text { outcome } \\
(n=28)\end{array}$ & \\
\hline \multicolumn{4}{|c|}{ Age in years } \\
\hline $19-20$ & $27(22.1 \%)$ & $4(14.3 \%)$ & \multirow{4}{*}{0.685} \\
\hline $21-25$ & $72(59 \%)$ & $19(67.9 \%)$ & \\
\hline $26-30$ & $19(15.6 \%)$ & $5(17.9 \%)$ & \\
\hline$>30$ & $4(3.3 \%)$ & $0(0 \%)$ & \\
\hline \multicolumn{4}{|l|}{ SES } \\
\hline 1 & $2(1.6 \%)$ & $0(0 \%)$ & \multirow{4}{*}{0.654} \\
\hline II & $25(20.5 \%)$ & $6(21.4 \%)$ & \\
\hline III & $56(45.9 \%)$ & $16(57.1 \%)$ & \\
\hline IV & $39(32 \%)$ & $6(21.4 \%)$ & \\
\hline \multicolumn{4}{|c|}{ Gestational age (weeks) } \\
\hline $28-34$ & $13(10.6 \%)$ & $3(10.7 \%)$ & \multirow{3}{*}{0.955} \\
\hline $34-36$ & $6(4.9 \%)$ & $1(3.6 \%)$ & \\
\hline$>36$ weeks & $103(84.4 \%)$ & $24(85.7 \%)$ & \\
\hline \multicolumn{4}{|l|}{ Parity } \\
\hline Primi & $80(65.6 \%)$ & $18(64.3 \%)$ & \multirow{2}{*}{0.897} \\
\hline Multi & $42(34.4 \%)$ & $10(35.7 \%)$ & \\
\hline \multicolumn{4}{|c|}{ Booked/unbooked } \\
\hline Booked & $96(78.7 \%)$ & $24(85.7 \%)$ & \multirow{2}{*}{0.402} \\
\hline Unbooked & $26(21.3 \%)$ & $4(14.3 \%)$ & \\
\hline \multicolumn{4}{|c|}{ Time interval } \\
\hline$<2$ hours & $75(61.5 \%)$ & $20(71.4 \%)$ & \multirow{3}{*}{0.038} \\
\hline $2-4$ hours & $44(36.1 \%)$ & $5(17.9 \%)$ & \\
\hline$>4$ hours & $3(2.5 \%)$ & $3(10.7 \%)$ & \\
\hline
\end{tabular}

\section{Socioeconomic Status and Educational Status}

The national family health survey data was taken into account for looking into the educational status. The level of education was higher in our study as compared to national levels. At our institution, almost $70 \%$ of the patient had at least a primary education compared to $59 \%$ in the NFHS study (Table 9). Limaye et al., similarly showed that factors like illiteracy, low socioeconomic status played a role in utilizing the available health services (Table 9). ${ }^{4}$

\section{Gestational Age}

About $84.7 \%$ referral was in the gestational age of more than 36 weeks, whereas about $10.7 \%$ of the referral was in the group 28-34 weeks of gestation. While analyzing these cases it was found that some of these cases could have been referred earlier in gestation, so that adequate intervention could have been done at a more appropriate time. However, lack of an adequate risk assessment tool to precisely predict these complications may lead to over-burdening of the tertiary healthcare center.

\section{Parity}

Primigravidas constituted $65.3 \%$ of the cases and multigravida constituted $34.7 \%$ of the cases in the present study. Percentages of complications were higher in 


\begin{tabular}{|c|c|c|c|c|c|c|c|}
\hline Maternal variables & $\begin{array}{l}\text { Live birth } \\
(n=101)\end{array}$ & $\begin{array}{l}\text { Low Apgar } \\
(n=21)\end{array}$ & $\begin{array}{l}I U D \\
(n=12)\end{array}$ & $\begin{array}{l}\text { Neonatal death } \\
(n=7)\end{array}$ & $\begin{array}{l}\text { Stillbirth } \\
(n=5)\end{array}$ & $\begin{array}{l}D A \\
(n=4)\end{array}$ & $p$ value \\
\hline \multicolumn{8}{|l|}{ Age in years } \\
\hline $19-20$ & $20(19.8 \%)$ & $4(19 \%)$ & $3(25 \%)$ & $2(28.6 \%)$ & $1(20 \%)$ & $1(25 \%)$ & \multirow{4}{*}{0.541} \\
\hline $21-25$ & $64(63.4 \%)$ & $13(61.9 \%)$ & $6(50 \%)$ & $4(57.1 \%)$ & $3(60 \%)$ & $1(25 \%)$ & \\
\hline $26-30$ & $15(14.9 \%)$ & $4(19 \%)$ & $2(16.7 \%)$ & $1(14.3 \%)$ & $0(0 \%)$ & $2(50 \%)$ & \\
\hline$>30$ & $2(2 \%)$ & $0(0 \%)$ & $1(8.3 \%)$ & $0(0 \%)$ & $1(20 \%)$ & $0(0 \%)$ & \\
\hline \multicolumn{8}{|l|}{ SES } \\
\hline I & $2(2 \%)$ & $0(0 \%)$ & $0(0 \%)$ & $0(0 \%)$ & $0(0 \%)$ & $0(0 \%)$ & \multirow{4}{*}{0.357} \\
\hline II & $23(22.8 \%)$ & $3(14.3 \%)$ & $2(16.7 \%)$ & $1(14.3 \%)$ & $2(40 \%)$ & $0(0 \%)$ & \\
\hline III & $50(49.5 \%)$ & $11(52.4 \%)$ & $2(16.7 \%)$ & $3(42.9 \%)$ & $3(60 \%)$ & $3(75 \%)$ & \\
\hline IV & $26(25.7 \%)$ & $7(33.3 \%)$ & $8(66.7 \%)$ & $3(42.9 \%)$ & $0(0 \%)$ & $1(25 \%)$ & \\
\hline \multicolumn{8}{|c|}{ Gestational age (weeks) } \\
\hline $28-34$ & $1(1 \%)$ & $0(0 \%)$ & $2(16.7 \%)$ & $1(14.3 \%)$ & $2(40 \%)$ & $0(0 \%)$ & \multirow{3}{*}{$<0.001$} \\
\hline $34-36$ & $4(4 \%)$ & $1(4.8 \%)$ & $5(41.7 \%)$ & $6(85.7 \%)$ & $1(20 \%)$ & $0(0 \%)$ & \\
\hline$>36$ weeks & $96(95 \%)$ & $20(95.2 \%)$ & $5(41.7 \%)$ & $0(0 \%)$ & $2(40 \%)$ & $4(100 \%)$ & \\
\hline \multicolumn{8}{|l|}{ Parity } \\
\hline Primi & $70(69.3 \%)$ & $13(61.9 \%)$ & $6(50 \%)$ & $5(71.4 \%)$ & $2(40 \%)$ & $2(50 \%)$ & \multirow{2}{*}{0.502} \\
\hline Multi & $31(30.7 \%)$ & $8(38.1 \%)$ & $6(50 \%)$ & $2(28.6 \%)$ & $3(60 \%)$ & $2(50 \%)$ & \\
\hline \multicolumn{8}{|l|}{ Booked/unbooked } \\
\hline Booked & $84(83.2 \%)$ & $16(76.2 \%)$ & 7 (58.3\%) & $5(71.4 \%)$ & $4(80 \%)$ & $4(100 \%)$ & \multirow{2}{*}{0.305} \\
\hline Unbooked & $17(16.8 \%)$ & $5(23.8 \%)$ & $5(41.7 \%)$ & $2(28.6 \%)$ & $1(20 \%)$ & $0(0 \%)$ & \\
\hline \multicolumn{8}{|l|}{ Time interval } \\
\hline$<2$ hours & $64(63.4 \%)$ & $12(57.1 \%)$ & $7(58.3 \%)$ & $5(71.4 \%)$ & $3(60 \%)$ & $4(100 \%)$ & \multirow{3}{*}{0.861} \\
\hline $2-4$ hours & $43(42.6 \%)$ & $8(38.1 \%)$ & $4(33.3 \%)$ & $2(28.6 \%)$ & $2(40 \%)$ & $0(0 \%)$ & \\
\hline$>4$ hours & $4(4 \%)$ & $1(4.8 \%)$ & $1(8.3 \%)$ & $0(0 \%)$ & $0(0 \%)$ & $0(0 \%)$ & \\
\hline
\end{tabular}

Table 7: Comparative study of age group

\begin{tabular}{lll}
\hline Age group (Years) & Limaye et al., series & Present Study \\
\hline $15-30$ & $89.20 \%$ & $97.30 \%$ \\
$31-35$ & $7.60 \%$ & $2.0 \%$ \\
$>35$ & $3.20 \%$ & $0.7 \%$ \\
\hline
\end{tabular}

Table 9: Comparative study of the educational status

\begin{tabular}{lll}
\hline Educational levels & NFHS-3 & Present study \\
\hline Uneducated & $41 \%$ & $6.00 \%$ \\
Primary level & $30 \%$ & $50.7 \%$ \\
Higher secondary & $22 \%$ & $20.7 \%$ \\
College & $7 \%$ & $17.3 \%$ \\
\hline
\end{tabular}

multigravida group. In our present series, the number of primi cases is approximately double of the previous Arup Kumar Majhi series, no. of multigravidas was less. We did not have any grand multigravidas as seen in the previous Arup Kumar Majhi series (Table 10). ${ }^{6}$ In Khatoon et al. series, primigravida had higher referral rates $65 \%$,
Table 8: Teenage pregnancy

\begin{tabular}{lll}
\hline & NFHS-2 & Present study \\
\hline $\begin{array}{l}\text { Teenage } \\
\text { pregnancies }\end{array}$ & $16.00 \%$ & $6.7 \%$ \\
\hline \multicolumn{3}{c}{ Table 10: Comparative study of parity } \\
\hline \multicolumn{3}{c}{ Arup Kumar Majhi } \\
Parity & Series & \\
\hline Primi & $33.22 \%$ & Present study \\
Multi & $55.76 \%$ & $65.3 \%$ \\
Grand multi & $11.02 \%$ & $34.7 \%$ \\
\hline
\end{tabular}

while multigravidas had $35 \%$ referral rate. ${ }^{7}$ In Delhi the proportion of birth order 3 and above has declined from $38.20 \%$ in 1988 to $24.81 \%$ in 1997.8

\section{Antenatal Care}

In the present study out of 150 cases the booked cases constituted $80 \%$, the remaining $20 \%$ were unbooked. 
A Study on Maternal and Perinatal Outcome in Referred Obstetric Cases of Gestational Age More Than 28 Weeks

\begin{tabular}{lllll}
\hline \multicolumn{4}{c}{ Table 11: } & Region-wise distribution of antenatal care \\
\hline & $\begin{array}{l}\text { Developing } \\
\text { countries (MDG India }\end{array}$ & & \\
& report) & (NFHS-3) & Karnataka & $\begin{array}{l}\text { Present } \\
\text { Study }\end{array}$ \\
\hline Antenatal care & $74.0 \%$ & $51 \%$ & $80.0 \%$ & $80.0 \%$ \\
\hline
\end{tabular}

Rao has recorded in his study (2000 AD) $)^{8}$ that even now almost $50 \%$ of women get no antenatal care (Table 11$)$. The current level of antenatal care in our country is 51\% (NFHS-3). Based on this antenatal care in our area is much higher than the nationwide level.

On comparing the percentage of booked cases in our study with the previous study it was seen that we had a much higher percentage of booked cases. This could be a result of better educational levels and socioeconomic status in the region. Considering such high levels of usage of antenatal care $(80 \%)$ (Table 12) facilities prevalent in the region one would expect fewer complication in this population; however, complications do occur, and so brings into question the efficiency and utility of the current ANC regimen.

\section{Pattern of Referral}

Referral from the government sector constituted a major part of about $86 \%, 14 \%$ of the referral was from the private sector. Of the public sector referral, most of them were from Taluk Head Quarters and Primary Health Centres. Majority of the referral was from within the district, followed by Tumkur. In a study conducted in a tertiary hospital in West Java referred obstetric cases constitutes $28 \%$ of admission. According to a study conducted in Choitram Hospital, $25 \%$ of the referral has been made secondary to obstetric causes. ${ }^{9}$

\section{Causes of Referral}

Out of 150 cases, $96(64 \%)$ of the referrals have been made secondary to emergency indications and $54(36 \%)$ of the referrals have been made secondary to elective indications. Preterm labor and PROM accounted for about 20\% of the referral. Hypertensive disorders were the next commonest cause of referral of about $13.3 \%$ of the cases. In the Khatoon et al. ${ }^{7}$ series, reasons for referral in the antepartum period was hypertensive disorders of pregnancy in $27 \%$, preterm labor $29.3 \%$, medical disorders complicating pregnancy $10 \%$ and severe anemia requiring a blood transfusion. Regarding reasons for referral $78 \%$ due to meconium stained liquor, while in multigravida patients reason of previous tender scars in 15\% of referrals. Jahn and De Brouwere et al. have reported 23\% of the referral for preterm labor and 18\% for hypertensive disorder in this study on referral in pregnancy and childbirth. ${ }^{10}$ Rathi et al. reported that majority of referrals were for hypertensive disorders $(26 \%)$ and preterm labor $(26 \%){ }^{9}$

\begin{tabular}{lll}
\multicolumn{3}{c}{ Table 12: Antenatal care (comparative study) } \\
\hline Antenatal care & Arup Kumar Majhi series & Present study \\
\hline Booked & $16.26 \%$ & $80.0 \%$ \\
Unbooked & $83.70 \%$ & $20.0 \%$ \\
\hline
\end{tabular}

\section{Quality of Referral}

Analyzing at the quality of referral according to the predefined criteria only $48 \%$ of the cases had adequate referral whereas about $24 \%$ of the cases had an inadequate referral and $28 \%$ of the cases had poor referral most of which were from the PHCs. This also could also be due to the uncertainty of the diagnosis of the condition. There were only two cases which were not examined before referral, and it shows relatively better functioning of our referral centers compared to those in other studies.

\section{Mode of Transportation and Time Took to Reach the Hospital}

Ninety percent of the patients managed to reach the referral center within 4 hours of referral. Such high rates of early referral (within 4 hours) are remarkable and have not been reported by any other studies, which reflects the robust referral system and the public understanding, participation and utilization of the healthcare system in the region. This is due to effective implementation and easy availability of emergency ambulance service 108 throughout the Karnataka state. Around $66 \%$ of the patients in the present study used 108 ambulances as the mode of transportation to reach the tertiary care center. In my study private vehicle is used by $16.7 \%$ of the patients, hospital ambulance is used by only $4.6 \%$ of the patients and $12.7 \%$ of patients chose public transport as a mode of transportation. Public transportation was used mainly by the patients with lower educational status who don't have the knowledge of free transportation services like 108 ambulances provided by the Government. In a study by Khatoon et al. most of the patients referred from different sources reached the hospital within 6 hours of referral while $52 \%$ of the patients reached the hospital within 12 to 24 hours of referred still $8 \%$ of patients had delayed arrival, i.e., after 24 hours of referral from the primary source. Rathi et al. reported only $36 \%$ of referral reaching within 6 hours of referral. The main reasons for this delay were a referral to an intermediary center, financial constraints, ignoring of warning signs of diseases by the patients and family members and poor transport facilities. ${ }^{9}$

\section{Condition of Mother on Admission}

From the table, it is evident that a very high percentage of patients arrived at the center in stable condition when 


\begin{tabular}{|c|c|c|}
\hline Condition & Rathi et al. & Present study \\
\hline Stable & 54.54 & 87.3 \\
\hline Poor & 36.36 & 10.7 \\
\hline Critical & 9.09 & 2.0 \\
\hline
\end{tabular}

compared to the Rathi et al. series (Table 13). Only $2 \%$ of the patients arrived at the center in critical condition which is relatively lower when compared to other studies.

\section{Condition of the Fetus on Admission}

In the present series on admission, fetal heart sounds were present in $93.3 \%$ of cases and absent in $6.7 \%$. One serious issue to be considered is whether these IUDs could be prevented. In a study by Bhatt et al. out of all the referrals $10.56 \%$ case, the fetus was no more alive on admission. Fetal distress was found in $14.63 \%$ of referrals on admission. ${ }^{11}$

\section{Management}

Of the total 150 cases, about 43 (28.66\%) cases required treatment before delivery. Antihypertensives treated $30.23 \%$ patients, $27.91 \%$ with tocolytics, $16.28 \%$ with tocolytics and steroids, $9.3 \%$ with insulin and $6.93 \%$ patients with SBE prophylaxis. 9.3\% of patients required a blood transfusion before delivery. In a study by Kambo et al. major indications for cesarean section included dystocia $(37.5 \%)$, fetal distress with or without meconium aspiration $(33.4 \%)$, repeat section $(29.0 \%)$, malpresentation $(14.5 \%)$ and $\mathrm{PIH}(12.5 \%) .{ }^{12}$ Modern obstetric practice for medical, social, economic, and legal reasons has witnessed an increase in the primary cesarean section rate everywhere. ${ }^{13}$ The rate of cesarean section in the urban educated population in Chennai is $45 \% .{ }^{14}$ In medical colleges and teaching hospitals in India, the overall rate for $C D$ is $24.4 \%{ }^{15}$ whereas the incidence rates of $C D$ in public, charitable, and private sector hospitals are $20 \%$, $38 \%$, and $47 \%$, respectively ${ }^{16}$ indicating a progressive increase in $\mathrm{CD}$ in different facility care centers.

\section{Maternal Outcome}

Out of 150 cases, there was no maternal mortality in our study in the span of two years. Bhatt et al. reported a maternal mortality rate of 19.41 per 1000 live births for all referrals (Table 14). ${ }^{11}$

Globally, direct causes account for $80 \%$ of all maternal deaths, and indirect causes account for the remainder. Of direct causes, hemorrhage is the most common. Indirect causes include diseases such as HIV / AIDS and malaria. ${ }^{17}$ Reported direct causes of maternal deaths are abortions $(18.0 \%)$, sepsis $(17.3 \%)$, hemorrhage $(12.8 \%)$, ruptured uterus $(8.3 \%)$ and other causes $(8.3 \%)$. Indirect causes
Table 14: Comparative study of maternal mortality rate

\begin{tabular}{|c|c|c|c|c|c|}
\hline & $\begin{array}{l}\text { Developed } \\
\text { region }\end{array}$ & $\begin{array}{l}\text { Developing } \\
\text { regions }\end{array}$ & India & Karnataka & $\begin{array}{l}\text { Present } \\
\text { study }\end{array}$ \\
\hline $\begin{array}{l}\text { Maternal } \\
\text { mortality } \\
\text { rate/100000 } \\
\text { live births }\end{array}$ & 9 & 450 & 301 & 228 & 0 \\
\hline
\end{tabular}

include hepatitis $(15.8 \%)$, anemia $(7.5 \%)$, heart disease $(6.0 \%)$ and others $(12.0 \%)$, in comparison to hemorrhage $(23.7 \%)$, anemia $(19.4 \%)$, toxaemia $(15.2 \%)$, abortions $(12 \%)$ and sepsis $(8 \%)$ for India as a whole. ${ }^{18}$

\section{Maternal Morbidity}

Maternal morbidity was in the form of wound sepsis in $8 \%$ of the cases, most of these cases being cases of obstructed labor. Wound gaping was seen in $2 \%$ and these patients went for secondary suturing. PPH was seen in six vaginal deliveries and two cesarean sections. One patient was detected to have couvelaire uterus during laparotomy for APH. The morbidity also increased the number of days of hospital stay. Percentage of maternal complications were greater in multigravidas, lower socioeconomic status patients and when the time taken to travel to reach the tertiary care center was more.

\section{Perinatal Outcome}

Perinatal mortality includes both late fetal deaths (stillbirths and IUD) and early neonatal deaths (Table 6). In our study, there were 126 live births, 5 , and 7 early neonatal death. Thus, there were 12 perinatal deaths giving the perinatal mortality as $95.23 / 1000$ live births. The study shows a live birth rate of $84 \%$, stillbirth rate of $3.3 \%$, neonatal death of $4.7 \%$ and IUD $8 \%$.

It was seen that the cause of death in the early neonatal period was mainly due to birth asphyxia which could have been prevented with better antenatal care and early referral. As far as obstetric events are concerned birth asphyxia was mainly due to obstructed labor, eclampsia, and APH. Perinatal morbidity was in the form of NICU admissions. Nearly $34.61 \%$ babies were admitted to NICU ranging from 4-28 days. The causes were birth asphyxia, low birthweight, septicemia, jaundice and transient tachypnoea of the newborn. Bellad et al. reported the perinatal mortality rate (PNMR) of 49.4 per 1000 births and the stillbirth rate of 43 per 1000 births. ${ }^{19}$ Bhatt et al. reported PNMR of 194.17/1000 live births. About 2/3rd of all perinatal deaths had occurred amongst fetuses with less than 1500 gm birth weight. ${ }^{11}$ Ali et al. reported perinatal mortality of $28.20 \%$ in their study. ${ }^{20}$ These high rates of perinatal mortality reflect the inadequate and insufficient obstetric services in the peripheral areas. 


\section{CONCLUSION}

With the implementation of the referral system an increasing proportion of patients are being referred to our hospital. This has compelled us to study the pattern of referral and the maternal and perinatal outcome of these patients. A cursory view of the available results immediately makes it clear that the referral system in the region is robust and performing well above the nationwide average and certainly is commendable. However, the self-referrals from rural areas were unaware of the existing antenatal services in the rural areas. Health education and awareness by mass media and nongovernment organizations can improve the health and social status of women in rural areas.

Although better than the national data, there is indeed no doubt that rural health care infrastructure is falling short of the existing requirement. However, educating the population about the existing healthcare delivery system and sensitizing the public towards improving maternal and child health would go a long way in optimally utilizing the existing infrastructure and improving the maternal and neonatal outcome. Qualities of the referral have been inadequate in many of the cases. This could be secondary to the fact that many of the referrals have been secondary to emergency indications. After analyzing the pattern of referral majority of the referral were from the public sector reinforcing the need for upgrading the facilities available at the peripheral centers. A clinical criterion for the referral and the adherence those proforma has to be followed.

The maintenance of proper antenatal records was not satisfactory in many of the subjects studied. A number of educational and research programs have to be conducted involving the health care professionals at the peripheral health centers to keep them updating their clinical knowledge and skills.

\section{REFERENCES}

1. Yayla M. Maternal mortality in developing countries. J Perinat. Med 2003;31(5):386-391.

2. Park K. Parks text book of preventive and social medicine; 19 th Edn. M/s Banarasidas Bhanot Publishers, Jabalpur.
3. Chatterjee A, Mukherjee J. Emergency Obstetric Care. J of Obst Gynae India 1998;48(61):31-34.

4. Limaye HR. Ghadiali MV, et al. Maternal and fetal outcome in obstetric emergency cases referred from rural area and recommendation to improve it. J of Obstet Gynecol India 1982;32:520-529.

5. Mukhopandhay P, Chakravarty RN. Hospital-based perinatal outcomes and complications in teenage pregnancy in India. J Health Popul Nutr 2010;28(5):494-500.

6. Majhi AK, Sanyal P, et al. Changing trends in maternal mortality in a teaching cum referral hospital. J Obstet Gynecol India, 1996;46:345-353.

7. Khatoon A, Hasny SF, et al. An audit of obstetrics referrals to Abbasi Shaheed Hospital. Pak J Surg 2011;27(4):304-308.

8. Bhaskar Rao K. Reproductive health of women in India during the last 50 years. J Obstet Gynecol India 2000;50:99-103.

9. Charu R, Kamal G, et al. Review of reffered obstetric cases -maternal and perinatal outcome. Bombay Hospital J 2010;52(1):53

10. Jahn A, De Brouwere V.. Referral in pregnancy and childbirth : concept and strategies. Studies in Health Services Organization And Policy 2010;17:229-246.

11. Shilpa SB, Anand PK. Study of obstetric referrals to teaching institute. Indian J Appl Res 2013;3(7):469-471.

12. Kambo I, Bedi N, et al. A critical appraisal of cesarean section rates at teaching hospitals in India. Int J Gynecol Obstetr 2002;79(2):151-158.

13. Mahale AR, Ghodke UP, et al. J Obstet Gynecol India 2008;58: 507-510.

14. Pai M, Sundaram $P$, et al. High rate of caesarean section in an affluent section of Chennai: is it cause for concern? Nat Med J India 1999;12:156-158

15. Bedi M, Dhilon BS, et al. A critical appraisal of caesarean section rates at teaching hospitals in India. Int J Gynecol Obstet 2002;79:151-158.

16. Vidya S, Sathiyasekaran BW. High caesarean rate in Madras (India). A population based cross sectional study. BJOG 2003;110:106-111.

17. A preventable tragedy-Maternal and newborn deaths in west Africa.Disease control priority project, June 2007. www.dcp2. org

18. Annual Report M/o Health \& F.W., Govt. of India, New Delhi, 1997-98, 45.

19. Bellad MB, Srividhya K, et al. Factors associated with perinatal mortality: a descriptive observational study. South Asian Fed Obstet Gynecol 2010;2(1):49-51.

20. Gadhi Ali MV, Sankhalkar PC 1978: Paper Read In AICOG Chandigarh Dec, 1980. 